\title{
SPARK CHAMBERS AND EARLY EXPERIMENTS
}

\author{
Donald Meyer \\ University of Michigan, Department of Physics \\ Ann Arbor, MI 48109-1120
}

In 1954 I was at Brookhaven for a couple of years, shortly after the bubble chamber was invented. Don Glaser brought a small bubble chamber to Brookhaven with a group including Marty Perl, Dave Rahm, and John Brown. They needed help learning their way around Brookhaven, and not yet being deeply involved in a project, I joined their group to learn how bubble chambers worked. As a result of this interaction, I came to Michigan in 1956 as an Assistant Professor. When I arrived in Michigan I worked with Don Glaser's group for a year, after which Marty and I decided we wanted to do our own thing, as young physicists often do. Marty went to work with Larry Jones, and I went to work with Kent. While still working with Don Glaser, I had been trying to make a gas tracking detector by putting a large microwave field on a gas filled cavity, the idea being that the microwaves would localize the gas discharge. I fiddled around with this for about a year and managed to get the chamber to the point that it was sensitive to radiation, but I never could get any spacial resolution. As soon as the gas started to ionize, ultra violet light went in all directions, and the whole chamber lit up. About this time, I got a call from Leon Lederman who, it happened, was doing the same thing, with the same results at Columbia. While I was pondering ways around the problem, Fukui and Myamoto published their first paper on the spark chamber. When I read the report I talked to Kent, and he said "You know, MURA is sort of winding down, I'd like to start doing some physics, let's try to build a spark chamber and see if we can do some physics with it". In approximately a week, Kent and I put together the necessary ingredients to make a spark chamber work. Kent's very thorough knowledge of how to use high voltages made this particularly easy. He even knew where to go in the department to find the proper thyratrons to make the circuits. This was the start of our collaboration which lasted for 6 or 7 years, until I went to CERN on sabbatical.

After we'd made the original little spark chamber, which was about 3" in diameter, we decided we should plunge into an experiment. Again, being young people and very enthusiastic, we put together a large spark chamber to do experiments at the Cosmotron. It was about 2 feet on a side, with thin foils for electrodes, and again, being very impatient, we didn't even bother to make a jig to stretch the foils. We just glued the chamber together, with one of us holding the foils tight, while the other epoxied it together. The problem was, the epoxy took about an hour to dry, but we decided that this was the fastest way to get a chamber made so, I would hold the foil for about 15 minutes, then Kent would 
come into the room and hold the foil for about 15 minutes. After an hour it was set. Then we'd start on the next foil. In a few days we had a chamber that was about 2 feet thick and it turned out to be the best spark chamber that I ever saw. It was exceedingly efficient, worked exceedingly well, and it was only later that I found out how important it was to control gas impurities, and put in the right kinds of things like methane and so forth, in the right proportions, in order to really make things work right. But this chamber worked the first time we turned it on. It was just absolutely beautiful.

I know everybody has seen spark chambers now, but at that time no one had seen a spark chamber work. Kent already had tenure. I didn't. I was still an Assistant Professor, and Kent said "I'm going to get you tenure, we're going to have you give a colloquium on the spark chamber, and we're going to show them the spark chamber". So we took the spark chamber to the colloquium and I thank Kent because, I got tenure 2 months later. Kent operated the spark chamber, I talked, and the combination was devasting. As soon as we turned out the lights, and turned on the spark chamber, the whole room broke into applause. There was no question as to whether it was a success or not. We took the spark chamber to the Cosmotron, and did a couple of experiments that involved looking at associated production of $\Lambda^{0} \mathrm{~s}$ and $\mathrm{Y}^{*} \mathrm{~s}$. This was our first experiment together. It was a big success because at that time there were very few associated production events which had all been obtained in diffusion cloud chambers. There just weren't very many.

We managed to collect something of the order of a 1,000 to $2,000 \mathrm{~K}^{0}-\Lambda^{0}$ events in a very short run. For a first experiment, it was very good. The things we put up with at the time were characteristics of the era, and people these days do not really appreciate these things. We didn't have very much money in our DoE contract, we rented a house on the north shore of Long Island. Tris Coffin had joined us by that time. Tris, Kent and I, with 3 graduate students (one of whom is here, Larry Curtis), the six of us, lived in a 1 bedroom house that had enough sleeping capacity for about 4 people if you used the couch in the living room. It was quite a summer. There was a nice beach about 2 blocks away. We would go down to the beach to swim, but we really kept the beds warm all the time. It was lucky we were running 3 shifts a day or we would never have been able to stand each other. The experiment was a success. I was back looking at Larry's thesis a few days ago, and I found we actually measured the spin of the $Y^{*}$. I had forgotten that. We measured the spin and the parity of the $Y^{*}$. The experiment was really a success.

I think the most interesting thing about it, was working with Oreste Piccioni. Oreste was using the same beam we were. We had an agreement with the Cosmotron that we would run for 3 weeks and then be off for 3 weeks. Oreste would take the beam 3 weeks, then we would take 3 weeks. Oreste has no sense 
of time. He would come in when he felt like coming in, and would leave when he felt like leaving. Sometimes there was no one running on the Cosmotron, the beam was going around the machine, and the beam was coming out, but there was no one there, and there were other times when we were both trying to use the machine. It was amusing. The other thing that happened was that Kent and I became known as spark chamber experts. Mel Schwartz was just starting work on the Neutrino chambers for the AGS experiment, which was so successful. We had many conversations with Mel giving him advise on what to do, what not to do, and so forth.

One of the things that we realized during this experiment was that you collected enormous amounts of data, very very fast. When we finished the experiment, we decided to spend some time developing an automatic scanning system for spark chambers. At that time, all spark chamber data was recorded photographically. As spark chambers developed, of course, magnetic readouts were used but in these early days, up to 1966 , when I went to CERN, all spark chambers employed photographic techniques. Kent and I tried to put money together to buy a computer, so we could develop an automatic scanning system. The best that DoE could do for us was a half of a PDP-1, a giant computer that occupied an enormous fraction of a room and did almost nothing by present day standards. We bought half of the PDP-1. The other half was funded by psychology. So we had psychology experiments going on in the same room that we were trying to do automatic scanning. We eventually bought a somewhat bigger computer as we became more experienced, and could get more money together. We were able to develop a reasonably good automatic scanning system for which Kent deserves most of the credit.

One of the things I should remark on is that Kent never really gave up being an accelerator physicist. Wherever we went, whether it was Brookhaven, or Argonne, he was always designing magnets, always designing beams for the experiment. He loved that kind of work, he was good at it, he loved it, and any time there was a beam to design Kent was there. This was really his forte; this is what he really enjoyed the most.

In looking back over students theses, and looking back at the way in which experiments were done in those days, there are two things that contrast greatly with the present. Between 1961 and 1966, Kent and I did 4 complete experiments on 3 different accelerators. This was typical of the time. When I look around now and see experiments, including our own last experiment, that go on for a decade I am amazed. I don't think it's just because we worked faster. The experiments have increased so much in complexity, and the accelerators have gotten so much more complex to run, that it is inevitable.

The other thing that has changed is the group size. We had 3 students and 3 faculty members on our first Brookhaven experiment which was relatively 
typical of the time. When I look at present collaborations I just shake my head. How do you know all the people who are on them? What are they all doing? Why don't they get in each other's way? That's what surprises me the most. Why aren't they fighting for positions around the experiments? I just don't understand. Well I do understand of course. I've been involved with it myself. It's really quite a different lifestyle.

The last experiment that Kent and I worked on together was the first experiment of the ZGS. We did a very extensive elastic scattering experiment, Tris Coffin, Kent and I worked together on a very extensive experiment in pion-proton elastic scattering. Looked at in retrospect, the physics was not as interesting as a lot of things one might do. Again this is a contrast between the physics then and the physics now. Particle physics, when we first worked in the field, from 1961 almost up until the discovery of the psi was to a certain extent unfocused. You didn't know where you were going. You were collecting data, hoping eventually it would fit into some kind of a pattern that would be useful. Now the experiments that are done, because there is better theoretical understanding largely due to the earlier exploration, are much more focused. You are looking for very specific things. You are disappointed if you don't see them. I have a hunch that we may go back to the other scheme. Maybe we are again at a stage in physics where there is going to have to be a lot of data gathering and searching. We are entering a new realm of High Energy Physics now, with these bigger machines.

When I returned from CERN, Kent and my physics interests diverged. We have never collaborated on experiments again, but were always close friends. We ate lunch together many times a week. Our families grew up together. In the past few years while Kent was associate chairman, and I was in charge of space planning for the department, we consulted with each other many times each day. I always enjoyed working with Kent. He was a great person. 